Seminars, Conferences, Addresses

\title{
The Scandinavian Conference on Middle East Studies
}

\author{
$24-27 \mathrm{Rabi}^{\top}$ al Ākhir 1413 / 22-25 October 1992 \\ Copenhagen University, Copenhagen, Denmark
}

The Nordic Association of Middle East Studies, which was established in 1989 in Uppsala, Sweden, recently held its second conference. Delegates from Denmark, Sweden, Norway, and Finland participated. John O. Voll (who has with Swedish ancestors), chairman of the Middle East Studies Association (MESA), came as guest lecturer.

The conference's leitmotif was "Diversity and Unity of the Middle Eastern World," which was also the theme of Voll's lecture. By reconceptualizing the understanding of Middle East as a holistic region, one in which sociopolitical, economic, and cultural patterns have been regarded within a narrow "Muslim" or "Islamic," framework, he objected to standardized concepts and generalizations. He used the case of the Egyptian peasant-how new developments and changed structures have transformed the peasant of the 1970s into the different peasant of the 1990s. $\mathrm{He}$ also argued that concepts themselves can be actors in history when they have been conceptualized. Thus they do not always describe reality. 
This lecture was a good starting point for the conference's many workshops and plenum sessions. The subjects included language, literature, classical studies, mysticism, anthropological studies, regional economical and political studies, Islamism in various forms, womens' studies, and the situation of Christian Arabs in the Middle East.

Marianne Lanantza (Sweden) gave a lecture on "New Economic Regional Cooperation: Strategies in the Middle East after the Gulf War and the Soviet Union's Dissolution." It was a profound description of economic relations between the West and the Middle East and their subsequent political consequences. She reinforced the view that the world is ruled by economic considerations rather than by politics and politicians.

Christel Braae (Denmark) discussed, in her "Cultural Heritage and National Identity," her fieldwork in the Gulf states. She showed how the concept of turäth (heritage) was used as a key term in the search for a national identity. However the common cultural heritage was not Islam, she maintained, but rather a primeval Bedouin ancestry derived from the pre-Islamic culture. She explained how the shaykhs propagated Bedouin culture through television and newspapers and how Bedouin, as opposed to Islamic, ceremonies and festivals were stressed.

Islamism was also a current theme of the lectures. Bjørn Olav Utvik's (Norway) "A New Brand of Islamism: The Egyptian Labour Party," featured a description of a leftist party that had taken over Islamic symbols. He stated that it had been neglected in present research, despite the fact that its magazines and newspapers have increased its circulation by more than four times. His conclusion was that this party had to be regarded within the framework of Islamic movements (al harakāt al Islämiyah). The party's aim is to be a mass movement. He further argued that it was a link between the Muslim Brotherhood and Nasserism.

In the workshop on Islam and science, three themes were featured. Philippe Provencal (Denmark) spoke about "The Biological Sciences in the Classical Islamic Culture." He said that his research showed that 77 percent of the results of classical Muslim scientists' studies agree with the latest biological research and 11 percent of the results are almost in agreement with latest research. Irmeli Perho (Finland) spoke on "The Prophet's Medicine: Islamization of a Scientific Tradition." In this interesting paper, she showed how prophetic medicine had continued to exist, at least in the literature, even though the Islamic-Greek medical tradition was dominant. Leif Stenberg (Sweden) asked "Do 'Islamic' Atoms Exist?" He gave a short analysis of the Islamists' argument for an Islamic scientific tradition. He cited opponents of this tradition and mentioned, among others, Nobel Prize winner Abdus-Salem's arguments against an Islamic science.

Islamism in western Europe was examined by Lars Pedersen (Denmark), who talked about the Tablighi Jama "at and a Turkish sociopolitical movement. The Tablighi Jama'at is very active in Scandinavia, which has a large Indo-Pakistani immigrant population. Pedersen did not, however, try to analyze the contents and effects of the groups' da 'wah, but only gave a plain description of its activities. 
The question of women was discussed at one workshop and was also the topic of a plenum lecture-"Gender in the Islamic Tendency" - by two Danish women: Connie Carøe Christiansen and Lene Koefoed Rasmussen. They concluded, through interviewing female Islamists in Denmark, Egypt, and Turkey, that Islamic "fundamentalism" could be interpreted as a feminist revolt. They pointed to the consequent view of all the interviewed female Islamists, whether from Egypt, Turkey, or living in Denmark: Muslim women in the present reality are suppressed, but ideal Islam is the opposite, as this "pure" Islam gives all proper rights to women.

At the workshop, Eva Evers Rosander (Sweden) gave a lecture entitled "Women, Law, and Identity in North Africa." She dealt mainly with the Moroccan feminists' fight for changed legislation. What was not sufficiently accentuated, however, was the opposition in Morocco to their fight for a more Western-oriented family legislation and the right of a woman to obtain a divorce. In addition, the common women often have other interests and viewpoints. For instance, they stress the importance of raising objections to the frequency of male divorce in order to secure their own social positions. This lecture paved the way for a discussion on how female Islamists, who often have a very high educational level, refuse conferred legal rights, as in Tunisia, and demand Shari'ah legislation, which, according to a Western mind, is totally hostile to women. The debate showed that Scandinavian research on Muslim women tends to be within a Western framework, with no understanding of or emphasis on the interaction between Islamic theological and sociopolitical ideas.

Elisabeth Ozdalga's (Sweden) lecture on the head-cover conflict in Turkey gave an indication of the vast range of Turkish views on this issue. She linked the phenomenon of Islamic resurgency to nineteenthcentury Europe or, more specifically, Austria, where "religious" ideas had been part of sociopolitical life.

This concept of the Muslim world as the West's alter ego was an implicit and underlying assumption in many lectures. It is obviously a means to give the contemporary Islamic movement a less negative image. By describing Western "religious" development from the committed attitude of the nineteenth century to the overarching atheistic ideas of the 1970s and 1980s in a Muslim context, it indicates that Islamism as a sociopolitical phenomenon should soon die out.

Another common notion held by the conference's participants was that women's head-covering has solely been a sign of political opposition. It seems that Western social scientists and, to a certain extent historians of religion, tend to give Sufism the exclusive right to spiritual sentiments, leaving out the theological dimension in the discussion of contemporary Islamic phenomena. This reductionistic methodology cannot be satisfactory for the study of Islamic concepts or phenomena. Even though Western researchers of Islam prefer not to be called orientalists, due to a connotational change of the concept, it seems that many are stuck in the old pattern of thought despite the liberal and tolerant mood dominating 
the last decades. We can just hope that as time passes, misunderstandings and misconceptions will dissolve.

The conference as a whole, however, can be regarded as quite successful. The presence of John $O$. Voll was very stimulating, and he gave the Nordic researchers a broader outlook, one which will be useful for the future Islamic research environment in Scandinavia.

Anne Sofie Roald Institute of Theology University of Lund Sweden

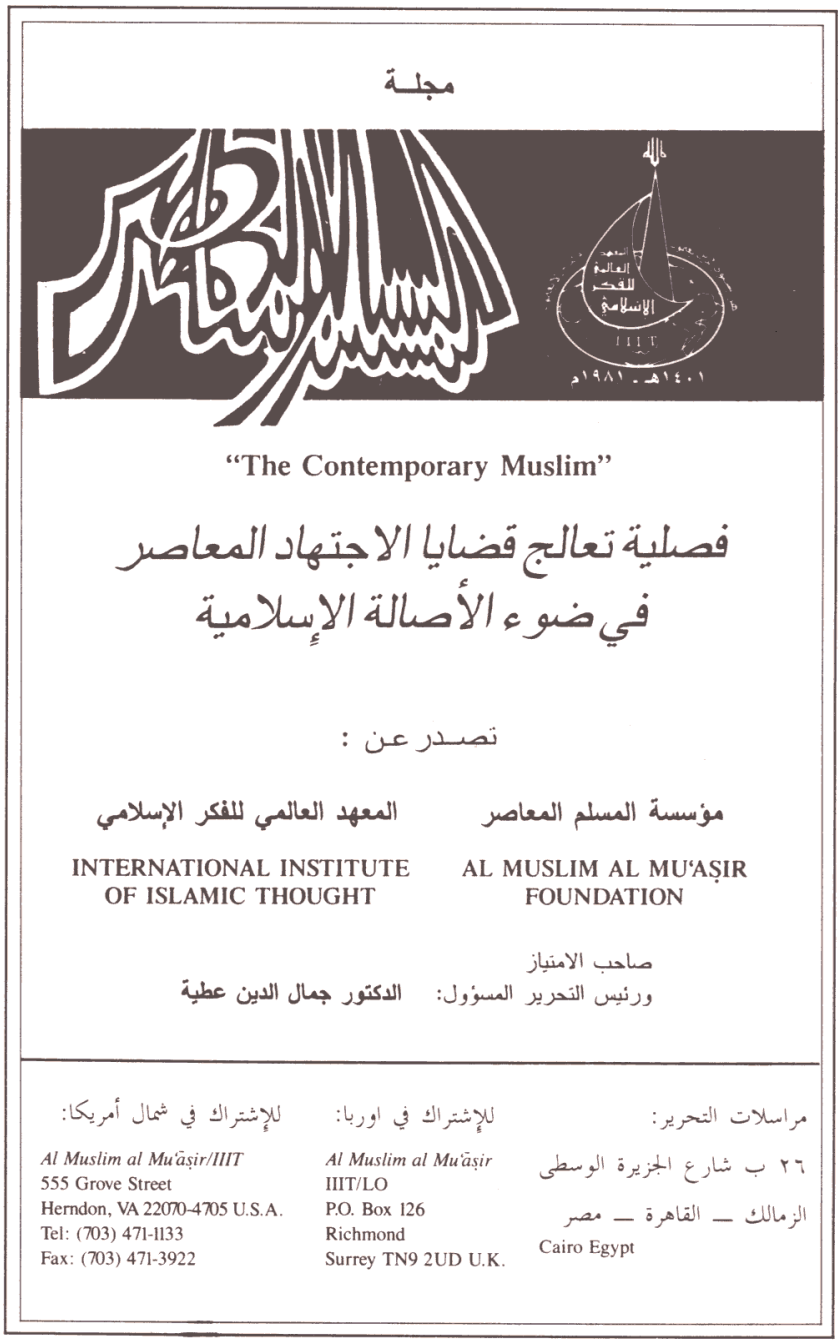

